\title{
Selecting Road-Noise Abatement Measures: Economic Analysis of Different Policy Objectives
}

\author{
Ronny Klæboe*, Knut Veisten, Astrid. H. Amundsen and Juned Akhtar
}

Institute of Transport Economics, Gaustadalleen 21, 0349 Oslo, Norway

\begin{abstract}
To satisfy new legislation, the Norwegian Public Roads Administration implemented a national façade insulation program encompassing 2,500 dwellings exposed to high levels of road traffic noise. Thereby, the road owner brought the equivalent noise levels from road traffic in compliance with a new indoor limit of $42 \mathrm{~dB}$. Cost-effectiveness analyses show that façade insulation was the least expensive noise-control alternative per dwelling. However, cost-benefit analyses show that the benefits were less than 20 per cent of costs. One reason for the poor benefit-cost ratio is that only the residents of the targeted dwellings benefit from at-receiver measures. Measures at the source and/or targeting the propagation paths also provide noise benefits for residents living along the same streets as the most noise exposed and inadequately insulated dwellings.

A mixed noise abatement policy employing low-noise asphalts in addition to façade insulation is therefore considered. For 750 dwellings where two or more of the dwellings were located along the same road stretch, low noise asphalts replaced façade insulation as noise abatement method. Façade insulation was kept as noise abatement method for the remaining 1,750 dwellings. The mixed noise abatement policy costs more, but now provides total benefits that match the total costs.

Even higher benefit-cost ratios are obtained when reframing the economic analyses within the context of a national policy to reduce noise annoyance, and when focussing solely on more densely populated areas where low- noise asphalts is a viable alternative to façade insulation. Since environmental authorities are in the process of further lowering the indoor noise limit, the road authorities should consider preparing an organisational and financial framework for implementing low-noise surfaces based on cost-benefit calculations. Such a policy would have the added benefit of improving urban soundscapes for a significant number of residents, workers, cyclists, pedestrians and children.
\end{abstract}

Keywords: Environmental limits, façade insulation, low-noise asphalt, noise measures, noise policy, dual objectives, soundscape.

\section{INTRODUCTION}

Traffic noise became the subject of Norwegian pollution regulation in 1997, regulation specifying that indoor equivalent noise levels should not exceed 42 decibels (dB). Where indoor noise levels exceeded the new environmental limit, infrastructure owners, among them, the Norwegian Public Road Authorities, were obliged to comply with the new regulations before the year 2005. One measure reducing indoor noise exposure, indoor noise annoyance and sleep disturbance is façade insulation [1-3]. To meet the new noise limits, the Norwegian Public Road Authorities introduced a façade insulation programme affecting 2,500 dwellings nationally and, to capitalize on the research opportunity presented, the Norwegian Façade Insulation Study [4] was realised.

The first round of results from the Norwegian Façade Insulation Study shows that respondents receiving façade insulation benefited significantly and substantially from the measure [5]. However, since noise abatement using façade insulation is costly, economic analyses were undertaken as part of the Insulation Study. Here, we examine this clean-up

*Address correspondence to this author at the Institute of Transport Economics, Gaustadalleen 21, 0349 Oslo, Norway; Tel: 4722573811, Fax: 4722609200; E-mail: rk@toi.no effort along the roads, focussing on how an alternative mix of noise-abatement measures would have been in terms of costs and benefits compared to façade insulation alone.

When the objective of fulfilling a new pollution regulation is being considered, a cost-effectiveness analysis (CEA), which is about finding the least costly way of meeting the regulatory limit, is often carried out. Measures more costly than the least costly are disregarded, even though the additional benefits may outweigh the added cost. Cost-benefit analysis (CBA), on the other hand, compares the various benefits of a measure to the costs [6]. In CBA, the measure with the highest ratio between benefits and costs will often be considered the most advantageous, regardless of whether it is relatively costly or not. When considering CEA vs CBA, it is relevant to point out that Norway has been moving towards a national target of noise annoyance reduction by 25 per cent before the year 2010 . This reduction was to be accomplished mainly by addressing noise emissions at source. The target has since been reduced to 10 per cent reduction in noise annoyance, and the time limit for attaining the targe pushed forward to 2020. Since road traffic noise is responsible for 80 per cent of noise-annoyance in Norway [7], and the main cause is road surface/tyre interaction, the authorities may need to find low-noise road surfaces that will survive winter conditions in the country [8]. 
The objective of this article is to show that noise abatement policy using only facade insulation has an alternative in terms of economic viability. This is to use lownoise asphalt as noise abatement measure in more densely populated areas, and facade insulation in less densely populated areas. We show that CEA and CBA yield different policy proposals: While CEA lends support for the use of façade insulation alone, CBA lends support to a noise abatement policy making also use of low-noise asphalts. This is because the benefits for all dwellings along the treated road sections benefit from the noise reductions, not only those that are worst off. To our knowledge, this article is one of few in the literature showing how selection of economic analysis is closely linked to the policy objective. Effectiveness (from CEA) or efficiency (from CBA) depends on the framing of the decision-making within either a single objective (relevant for CEA) or a dual/plural objective (relevant for CBA).

\section{NOISE-ABATEMENT TECHNOLOGIES, EFFECTS AND COSTS}

\subsection{Façade Insulation}

In calculating the noise exposure of dwellings located along roads where traffic levels are sufficiently high to warrant closer study, the Norwegian Public Roads Administration identified 2,500 where indoor noise levels might be exceeded. Applying the national average number of residents per dwelling and 2.2 persons means that about 5,500 people in different Norwegian counties are affected. To characterize indoor traffic noise, the 24-hour equivalent sound pressure level $\left(\mathrm{LA}_{\mathrm{eq}}\right)$ was calculated inside the most exposed façade of each dwelling (see [4,5] for a more detailed description). The measures chosen to reduce indoor noise levels were façade insulation, new noise-insulating windows and new active ventilation systems. Where the existing façade of a building was of sufficient quality, insulation of the weak spots - the windows and ventilation system - was to good effect. However, most dwellings received complete façade insulation.

Results from the façade insulation study [5] indicate that actual reductions in indoor annoyance and in sleep disturbance match the attained average reduction in indoor equivalent noise levels of $7 \mathrm{~dB}$. Indoor noise-level measurements undertaken by an independent noise-exposure expert suggest that the noise reduction achieved indoors could have been as much as $8 \mathrm{~dB}$. However, given the limited number of dwellings in which the control measurements were taken, we hold on to the originally estimated reduction of $7 \mathrm{~dB}$.

The average cost per apartment for façade insulation is estimated at NOK 225,000. This translates to EUR 28,125 when applying an exchange rate in the year 2006 of NOK 8 per 1 EUR. We assume a 25-year life span of façade insulation. All costs in conjunction with the noise-insulation measures were carried by the state. There was thus no cost to homeowners. In addition to indoor noise reduction, façade insulation can have additional beneficial effects, such as improved thermal insulation and the modernisation of older or badly maintained parts of the buildings/dwellings. However, we have no data available assessing these potential side effects.

\subsection{Low-Noise Asphalts}

A substantial reduction of noise has been achieved in Norway with low-noise asphalts, even under Nordic conditions. The use of studded tyres during winter and winter maintenance seem no longer to preclude the use of these measures [8, 9]. Low-noise asphalts also have an advantage over façade insulation in that indoor and outdoor noise affecting all buildings near surface-treated roads is less - not just the indoor situation in dwellings exceeding the new indoor noise limit. Since low-noise asphalt is applied along contiguous stretches of some length, a further advantage is that the soundscape of the entire neighbourhood improves, i.e. the sound environment of recreational areas near streets, areas used by children playing outdoors, pedestrian precincts of residents visiting neighbours and nearby shops, public transport, and footpaths for walking and cycling [10-20].

Since the reduction of the noise levels from road traffic must be large enough for the new indoor limit to be met, the "best available" double-porous asphalt concrete is used here. The technical lifetime of which is shorter than for the existing standard (dense) asphalt and roads with higher traffic levels have to be resurfaced ("reinvestment") every third year (AADT $>10,000)$. Noise reduction is assumed to be $4.5 \mathrm{~dB}$ on average over the lifetime $[9,21]$. Noise reduction from double-porous asphalt is greater the first year(s), but wear, studded tyres and winter maintenance diminish the noise absorption over time. For most noise-abatement projects utilising low-noise asphalts, the reduction in noise emissions relative to standard dense asphalt is thus higher initially than at the end [20].

Choice of pavement type can affect air quality, since road-wear produces particulate matter $\left(\mathrm{PM}_{10}\right)$. Although the relationship between asphalt wear and $\mathrm{PM}_{10}$ emission is not exact, the asphalt-wearing property of Norwegian standard asphalts and low-noise asphalt alternatives has been measured $[22,23]$. Impact on health due to $\mathrm{PM}_{10}$ from roads is estimated as well, and has been given an economic value [24]. The selected low-noise asphalt alternative for this study, a best possible version of double-porous asphalt concrete with maximum aggregate size $11 \mathrm{~mm}$ in the top layer and $16 \mathrm{~mm}$ in the bottom layer, is estimated to yield 25 per cent less dust, and we assume a similar effect on $\mathrm{PM}_{10}$ [9] from road wear [21]. In the same way as for noise reduction at source, the benefits from reductions in particulate matters are applicable to all dwellings located along the treated road stretches, not only the dwellings where noise abatement is mandatory.

Low-noise asphalts cannot be applied through isolated patches in front of individual buildings but must be laid along a contiguous road section of some length; say $1 \mathrm{~km}$. Low-noise asphalt projects consequently entail greater minimum project costs. A change from standard dense asphalt (mostly stone mastic asphalt) to low-noise asphalt will also normally entail higher asphalt costs per square metre and a shorter lifetime of the asphalt. The best available double-porous asphalt per application costs about EUR 22.75 per $\mathrm{m}^{2}$ compared to 10.75 per $\mathrm{m}^{2}$ for standard asphalt. The lifetime would also be halved, i.e. from 7 to 4 years, assuming an average annual daily traffic (AADT) of 12,000 and average speed of approximately $60 \mathrm{~km} / \mathrm{h}$. 


\subsection{A Mix of Low-Noise Asphalts and Façade Insulation vs 100 Per Cent Façade Insulation}

The total benefit of low-noise asphalt projects depends critically on the number of dwellings along a particular stretch of road. In many urban areas, for example, the number of dwellings located along the roads/streets is probably high enough for it to be worthwhile considering low-noise asphalts. These dwellings/apartments are often situated at more or less the same distance from one another and relatively close to the dominant source of road noise. Other dwellings qualifying for the noise-limit regulation are located along more sparsely populated areas, where lownoise asphalts would not be expected to benefit many people other than the residents of the targeted dwellings with indoor equivalent noise levels exceeding $42 \mathrm{~dB}$ [25]. Furthermore, if many homes qualifying for noise-abatement measures are dispersed across cities and along streets, low-noise asphalt may not be a feasible policy option economically. The geographical clustering of the 2,500 dwellings with indoor noise levels above $42 \mathrm{~dB}$ is given in Table $\mathbf{1}$.

Table 1. Geographical Clustering of the 2,500 Dwellings with Indoor Noise Levels Above $42 \mathrm{~dB}$

\begin{tabular}{|c|c|c|}
\hline & No. of Dwellings & No. of Streets \\
\hline \hline $\begin{array}{c}1 \text { dwelling with } \\
\mathrm{dB}>42 \text { per street }\end{array}$ & 1,750 & 1,750 \\
\hline $\begin{array}{c}\geq 2 \text { dwellings with } \\
\mathrm{dB}>42 \text { along same street }\end{array}$ & 750 & 180 \\
\hline
\end{tabular}

In the economic analyses we assume that the dwelling density along roads where only one dwelling qualifies for noise abatement is too low for low noise asphalts to be a viable alternative.

However, where two or more dwellings indoor noise levels above $42 \mathrm{~dB}$ are located along the same road stretch, we assume that there will be several more dwellings in that street exposed to high levels of road traffic noise. For thirty per cent of the 2,500 dwellings, more than one, on the average more than four dwellings, are located along the same road stretch. For these 750 dwellings and 180 streets, alternative at-source noise-abatement measures were considered viable and that they could be implemented.

For these 180 roads, we further assume that the minimum stretch of road on which low-noise asphalt can be laid is 1 $\mathrm{km}$, and that 300 dwellings are located close enough to the road to benefit fully from noise reductions. One could argue that benefits from noise reductions at lower noise levels are not worth as much as those that occur at higher noise levels [26], however, in Norway the benefits from noise reductions of the same size are treated the same - as long as the resulting equivalent exposure values on the most exposed facade are above 55dBA.

An independent examination of city maps featuring two of the candidate road stretches with detached dwellings, confirmed that for these stretches approximately 300 dwellings would fully benefit from the reduced noise from low-noise surfaces, and that the assumption was not unreasonable. We therefore assume that all dwellings close to such a "noisy" street will benefit fully from the dB reduction. The total number of dwellings potentially benefiting from low-noise asphalts, in terms of $4.5 \mathrm{~dB}$ reduction and 25 per cent reduction in $\mathrm{PM}_{10}$, is here calculated as: 180 roads $\times 1 \mathrm{~km} \times 300$ dwellings $/ \mathrm{km}=54,000$ dwellings.

In the calculations we have not taken into account improvements in the noise environment for dwellings located further away from the main road.

We thus have two competing alternatives for road-noise abatement:

\section{Alternative 1:}

- $\quad$ Façade insulation for all 2,500 dwellings (100 per cent façade insulation).

\section{Alternative 2:}

- $\quad$ Façade insulation for the 1,750 individual dwellings (70 per cent façade insulation) that are scattered around the country (and where we may assume that population density is too low for low-noise asphalt solutions to be viable).

- Low-noise asphalt for the 180 streets with the remaining $750 \mathrm{dwellings}$ entitled to noise-abatement measures (30 per cent low-noise asphalt).

\section{METHODS}

\subsection{Economic Analysis in a Single-Objective vs Dual- Objective Situation, CEA vs CBA}

Economic analysis depend on 1) whether the sole objective of the authorities' noise policies is to bring indoor noise levels down to the new legal limit (single objective situation), and 2) whether, in addition, we should consider efforts aimed towards a broader national noise annoyance reduction target (dual objective situation). In regard to dual (or plural) objectives, an interesting hypothesis is that the added benefits of achieving reductions in general noise annoyance could influence the choice of abatement policy. If a noise abatement policy fulfils the criterion of benefits outweighing costs in the dual objective situation, it could be preferred over policy that is narrower in scope although cost effective within this scope.

When we consider the objective of complying with the new pollution regulation in isolation, a CEA is appropriate. CEA aims at finding the least costly solution to attaining a given objective, or at comparing the costs and impacts of two or more competing solutions [27, 28]. Since the impacts need not be converted to money values, only measures yielding similar outcomes can be readily compared. The result of the method is a ratio of incremental cost to incremental impact. In our case, the CEA finds how to minimize the costs of complying with the regulation:

\section{Cost-effectiveness ratio Alternative $\mathrm{X}$}

$$
=\frac{\text { Costs of implementation of measure per dwelling }}{\text { Indoor equivalent noise levels } \leq 42 \mathrm{~dB}}
$$

The total cost of the alternative is therefore divided among the 2,500 dwellings entitled to noise abatement by 
regulation. By definition, the ratio indicates that comparing cost-effectiveness between façade insulation and low-noise asphalt is problematic, because both yield non-similar outcomes apart from "noise reduction". First of all, the $7 \mathrm{~dB}$ noise reduction from façade insulation exceeds the $4.5 \mathrm{~dB}$ reduction from laying the "best available" double-porous asphalt. However, since attainment of a particular indoor noise limit is the target (single objective), and since exceedance of the $42 \mathrm{~dB}$ limit is normally not by more than $4.5 \mathrm{~dB}$ [5], also low-noise asphalt will lead to indoor noise levels coming within the regulatory limit.

CBA is more appropriate for the dual (or plural) objective in policy assessment. In CBA, all impacts that individuals hold preference over should be included and, to the extent possible, should be monetized to enable comparison of measures with different types of impact. This means that also non-acoustic benefits need to be assessed, e.g. $\mathrm{PM}_{10}$ pollution. A comparison of measures of different scale/scope can be based on a benefit-cost ratio, defined as:

Benefit-cost ratio Alternative $\mathrm{X}$

$=\frac{\text { Present value of all benefits }}{\text { Present value of implementation costs }}$

When benefits exceed costs (the net present value is positive), the benefit-cost ratio exceeds the value of 1 . For the present value calculations, we follow proposed European Standard [31] applying a project horizon of 40 years and a 3 per cent annual discount rate (yielding an annuity factor of 23.81).

A CEA or CBA of façade insulation has an ex post perspective, since the façade insulation has already been carried out in all 2,500 dwellings with indoor equivalent noise levels exceeding $42 \mathrm{~dB}$. However, an ex post perspective is both possible and useful, particularly for CBA, where the actual cost of complying with the regulation is held up against the benefits [29, 30]. The Norwegian Façade Insulation Study [4] also provides a unique opportunity for obtaining national baseline cost and benefit estimates for future noise reduction and abatement efforts and where economic efficiency and rational use of sparse public funds may outweigh legal, distributional or social justice concerns.

Another issue when considering alternative measures ex post, such as including low-noise asphalt in a mix with façade insulation, an alternative reference (baseline) for economic analysis is created. In the ex ante situation, both façade insulation and double-porous asphalt are assessed with respect to a "do nothing" baseline [25]. In the ex post situation, having already carried out 100 per cent façade insulation, the double-porous asphalt can be assessed in CBA with respect to this "façade insulation" baseline. In a situation where façade insulation fails to meet the benefitcost criteria, having larger costs than benefits, an alternative noise-abatement policy involving double-porous asphalt may stand out ex post as relatively more efficient (being compared to façade insulation) than when assessed against "do nothing" ex ante. We present CEA and CBA of "Alternative 1" (100 per cent façade insulation) and "Alternative 2" (70 per cent façade insulation/30 per cent low-noise asphalt) with an ex ante perspective, but our calculations also show results from the ex post perspective.

\subsection{Valuation of the Benefits}

The Norwegian Public Roads Administration uses a monetary evaluation in accordance with the number of decibels by which the equivalent noise levels are reduced. In 2005/2006 this was NOK 238 per dB per person affected per year, or NOK 524 per household, i.e. EUR 65.45. $\mathrm{PM}_{10}$ emissions are valued at EUR 51.25 per $\mathrm{kg}$, in application to Norwegian urban areas in general, but these values are much higher for some larger cities [24]. Related to the fact that the 30 per cent of dwellings allocated to low-noise asphalt (in "Alternative 2") are located in high-density areas (approximately 300 dwellings per $\mathrm{km}$ ), we use a correction factor that increases the $\mathrm{PM}_{10}$ valuation to EUR 140 per $\mathrm{kg}$ (which is still considerably below the official valuations for the largest cities in Norway).

With a $7 \mathrm{~dB}$ noise reduction from façade insulation, the estimated annual noise control benefit value (annually) per dwelling is EUR 445. In terms of decibel reduction, the noise control benefit is lower for low-noise asphalts than for façade insulation, at $4.5 \mathrm{~dB}$ on average for the affected dwellings, thus providing an estimated noise-benefit value of EUR 280 per dwelling per year. For a 40-year project horizon applying a discount rate of 3 per cent per year [31], the present value of current and future acoustic benefits would be EUR 10,590 for each dwelling receiving façade insulation with reinvestment every 25 th year, and EUR 6,657 with reinvestment every third year. As indicated, benefits from reducing noise at source are not limited to dwellings entitled to abatement measures (having indoor equivalent noise levels exceeding $42 \mathrm{~dB}$ ). Thus, in CBA we can add noise-control benefits to all dwellings located near the road.

\subsection{Sensitivity Analysis/Uncertainty Analysis}

Results from economic analyses are often presented as single numeric estimates. This is unsatisfactory, since point estimates lack information on the uncertainty associated with the estimate. Since it is possible to quantify our subjective assessment of this uncertainty, we can carry out a comprehensive sensitivity/uncertainty analysis with simultaneous assessment of the importance of input parameters based on simulations [32]. Different inputs are thus considered to be drawn from a probability distribution, and will therefore vary from simulation to simulation. The inputs that are varied are investment cost, lifetime of investment and noise reduction, and, for low-noise asphalt, the effect on asphalt wear and tear and subsequent $\mathrm{PM}_{10}$ levels adjacent to the roads, and the number of affected households/dwellings.

A Monte Carlo type of simulation can be accomplished using the program @ RISK $^{\mathrm{TM}}$ for Excel spreadsheets [33]. In addition to the fixed (deterministic) estimates of the benefitcost ratio and cost-effectiveness ratio, the procedure provides a probability distribution of these estimated ratios, for the two alternative policy options; "Alternative 1" (100 per cent façade insulation) and "Alternative 2" (70 per cent façade insulation/30 per cent low-noise asphalt).

In regard to distributional assumptions for the inputs, to simplify things we apply normal (Gaussian) distributions and represent uncertainty (risk) as a percentage of the average value (point estimates), thereby yielding standard deviations 
Table 2. Results from the Cost-Effectiveness and Cost-Benefit Analyses (Annuities); Ex Ante Perspective

\begin{tabular}{|c|c|c|c|c|}
\hline & \multirow{2}{*}{$\begin{array}{c}\text { Alternative } 1 \\
\text { Façade }\end{array}$} & \multirow{2}{*}{$\begin{array}{c}\text { Alternative } 2 \\
\text { Asphalt/Façade }\end{array}$} & \multicolumn{2}{|c|}{ Alternative 2 components } \\
\hline & & & Façade $70 \%$ & Asphalt 30\% \\
\hline Dwellings affected & 2,500 & 55,750 & 1,750 & 54,000 \\
\hline Noise-control benefits & 801,763 & $8,336,694$ & 561,234 & $7,775,460$ \\
\hline Other benefits $\left(\mathrm{PM}_{10}\right)$ & 0 & 155,802 & 0 & 155,802 \\
\hline Sum benefits & 801,763 & $8,492,496$ & 561,234 & $7,931,262$ \\
\hline Costs & $4,363,794$ & $8,374,507$ & $3,054,656$ & $5,319,851$ \\
\hline Net benefits & $-3,562,031$ & 117,989 & $-2,493,422$ & $2,611,411$ \\
\hline \multirow[t]{3}{*}{$\begin{array}{l}\text { Cost-effectiveness ratio (per } \\
\text { dwelling) }\end{array}$} & 1,746 & 3,350 & & \\
\hline & & & \multicolumn{2}{|c|}{ double porous asphalt } \\
\hline & & & $v s$ "do nothing" (ex ante) & $v s$ façade ins. (ex post) \\
\hline Benefit-cost ratio & 0.18 & 1.01 & 1.49 & 1.92 \\
\hline In percentages & $18 \%$ & $101 \%$ & $149 \%$ & $192 \%$ \\
\hline
\end{tabular}

of the distributions. Assumptions regarding point estimates and spread of noise reduction, $\mathrm{PM}_{10}$ emissions, pavement lifetime and investment costs are based primarily on experiences in a recent low-noise asphalt project by the Norwegian Public Roads Administration [9, 21]. The assumptions are:

- Total investment costs façade/asphalt: $\pm 15 \% / \pm 30 \%$

- Noise reduction façade/asphalt: $\pm 15 \% / \pm 30 \%$

- Technical lifetime façade/asphalt: $\pm 15 \% / \pm 30 \%$

- $\quad \mathrm{PM}_{10}$ change: $\pm 50 \%$

- $\quad$ Number of affected dwellings per $\mathrm{km}: \pm 30 \%$ (with lower and upper limits of 50 and 550, respectively).

\section{RESULTS FROM THE CEA AND CBA ANALYSES}

\subsection{Point Estimates}

There are two alternative projects: "Alternative 1" is full façade insulation for all 2,500 dwellings; "Alternative 2 " is façade insulation for 70 per cent (1,750 dwellings) and lownoise asphalt for 30 per cent ( 750 dwellings in 180 streets). Since the laying of asphalt also benefits other dwellings, the total number of dwellings benefiting from low-noise asphalt in the dual objective situation is calculated as 180 roads $\times 1$ $\mathrm{km} \times 300$ dwellings $/ \mathrm{km}=54,000$ dwellings.

Table 2 gives results from the CEA, the costeffectiveness ratio per dwelling for reducing the indoor equivalent noise levels to maximum $42 \mathrm{~dB}$ for the 2,500 dwellings, and from the CBA (net benefits and benefit-cost ratios). The estimates are given from an ex ante perspective, with a "do nothing" reference, but we include the benefitcost ratio for double-porous asphalt with façade insulation as reference.

When we consider the single-objective CEA, the results show that "Alternative 1", the 100 per cent façade project, yields lower costs and consequently has a lower (better) cost-effectiveness ratio than "Alternative 2", the 70-30 per cent mix. "Alternative 1" targets the 2,500 dwellings entitled to noise abatement. However, when considering the result from the CBA, we can see that the narrow focus of the at source measure produces benefits amounting to only 18 per cent of the cost of "Alternative 1". "Alternative 2", the combined asphalt/façade insulation project, yields a much higher benefit-cost ratio. Although costing more, the benefits from the change to low-noise double porous asphalt "flow" to many more dwellings than the 750 . Assuming $300^{1}$ dwellings per street, in 180 streets, the estimated benefits of reduced road noise are based on a total of 55,750 dwellings for the combined asphalt/façade alternative, including the 1,750 dwellings receiving façade insulation in "Alternative 2 ".

\subsection{Simulations of Uncertainty}

The better cost effectiveness of 100 per cent façade insulation, disregarding other noise policy targets (CEA), is underpinned by simulation using @RISK. The simulated cost-effectiveness ratio (cost per dwelling) for 100 per cent façade ("Alternative 1") is about half that of the mixed alternative ("Alternative 2"), i.e. EUR 40,000 vs EUR 77,000 , and with much lower standard deviation. The costeffectiveness ratio for 100 per cent façade is estimated as having 90 per cent of the probability mass between EUR 27,000 and EUR 56,000, while the distribution of the costeffectiveness ratio for the mix of double-porous asphalt and façade insulation has a large right-hand tail (towards EUR 470,000).

The simulated benefit-cost ratios also indicate more uncertainty for "Alternative 2" than for "Alternative 1", but the simulated mean benefit-cost ratio is 1.26 for "Alternative 2 " while only 0.13 for "Alternative 1 ". Even though the minimum value is lower for the mix of double-porous

${ }^{1}$ Even if the dwelling density is as low as 60 per km, the benefit-cost ratio of low noise asphalts is better than for facade insulation. 
asphalt and façade insulation, the simulated benefit-cost ratio for "Alternative 2" has more than $90 \%$ of the probability mass above the simulated mean of "Alternative 1". This indicates much higher probability of a better benefit-cost ratio for the mix of double-porous asphalt and façade insulation, as compared to 100 per cent façade, for which a benefit-cost ratio below 1 is "almost certain".

\section{DISCUSSION}

More dwellings are exposed to high levels of road traffic noise than the 2,500 entitled to noise abatement by regulation. The Norwegian government has a national target of reducing noise annoyance by 10 per cent before the year 2020. Our study indicates that, by mixed use of noise abatement measures (low-noise asphalt and façade insulation), a dual/plural objective noise abatement alternative encompassing both the 2,500 dwellings and larger densely populated areas may be better in economic terms than the narrow single objective use of façade insulation alone. One hundred per cent façade insulation is most costeffective (from the CEA perspective), but mixed use of lownoise asphalt and façade insulation is more efficient (from the CBA perspective). Even, when considering future noiseabatement projects specifically aimed at reducing high noise annoyance, and where social justice concerns mandate that all heavily exposed dwellings should be equally eligible for improvement, the inclusion of at-source noise abatement measures seems preferable from an economic perspective, lending more weight to CBA than to CEA.

The mixed use of double-porous asphalt and façade insulation ("Alternative 2") does not attain a "very" high benefit-cost ratio, although much higher than for 100 per cent façade insulation and also reaching break-even. When assessing public investments, a higher benefit-cost ratio than 1 is normally sought, to guard against uncertainties of the estimates [31, 9]. However, in a situation where the authorities want to set priorities or specific goals for the reduction of overall population noise annoyance, the results from the CBA indicate that use of low-noise asphalt is economically viable. One hundred per cent use of low-noise asphalt in densely populated areas ( $\geq 300$ dwellings adjacent to a $\mathrm{road} /$ street per $\mathrm{km}$ ), and assuming initial road noise at levels such that all dwellings adjacent to the road will benefit from tyre/road noise reduction, the estimated benefit-cost ratio approximates 1.5 (1.49). Estimates of the economic analysis were initially presented from an ex ante perspective, implicitly using a "do nothing" baseline. It is noteworthy that the real baseline alternative in our situation ("Alternative 1" carried out) entails high cost without corresponding benefits. Assessing 100 per cent use of low-noise asphalt against "Alternative 1" as reference, the estimated benefit-cost ratio approximates 2 (1.92).

In the CBA, it was not possible to calculate all possible benefits from the two different alternatives. For façade insulation, there is a quality improvement of the building, and improved thermal insulation may reduce heating costs. For low-noise surfaces, the reduced noise levels outside the dwellings and the benefits for residents when outdoors walking, cycling, visiting nearby shops, neighbours and the use of recreational areas and children's playgrounds are not included. Only noise improvements indoors are included in the cost-benefit analyses.

It can be questioned whether the costs and benefits deriving from an extraordinary national effort to bring indoor noise levels into line with new limits really are representative of the costs and benefits under normal circumstances. However, since the exceedances of the environmental limits were modest (not exceptionally high), we conclude that the results from our economic analyses should also be representative for future situations where exceedances occur.

With respect to the authorities' proposed policy of lowering the maximum allowed indoor noise levels, it can be concluded that there are some advantages in utilising an instrument originally devised for ensuring a minimum standard. These advantages lie in the legislative foundation of the measure, established legal procedures for resolving conflicts, the clear allocation of responsibility, and the added advantage in Norway of having competent professional organizations in charge of, and with funding for, implementing the measures.

The policy can also be said to be far more productive than having noise-reduction targets that, although in theory could be achieved with less use of public funds, have no substance in the form of an organisational framework, no funding, no management, and no instruments for applying the insights from economic analyses. However, it is reasonable to ask whether a measure achieves its objective, and also whether its implementation makes best use of public funds. According to the economic analyses, where benefits are matched against costs, this no longer seems to be the case.

If the authorities can produce an organisational and financial framework in support of national road traffic noise reduction targets, low-noise surfaces could provide greater benefits by reducing general road traffic noise annoyance also for the many who are exposed to very high noise levels when indoors. However, we have to add the caveat that extensive multi-year trials of the low-noise surface alternatives, and corresponding benefits for the residents, have yet to be undertaken.

If we are to manage general efforts to reducing noise annoyance in Norway and reach reduction targets, new mandatory indoor noise limits may be opportunities too good to be ignored. Such events where "do-nothing" is no longer an option provide time-limited opportunity for triggering the use of funds for projects that in the short term may exhibit "quite high" benefit-cost ratios.

In this article, we have calculated the benefits of noise reduction in terms of improvement of the indoor situation. However, in the view of the Norwegian Pollution Control Authority, it is outdoor and indoor improvements together that count, which means that our main conclusions - that a mix of façade insulation and low-noise road surfaces is often to be preferred - holds a fortiori. When we add the benefits to the neighbourhood soundscape of having kilometere-long stretches of outdoor areas along main roads rendered more silent by low-noise asphalts, the advantages are even greater. 


\section{CONCLUSIONS}

The CBA indicates that benefits from façade insulation in Norway amount to less than 20 per cent of costs. The implication is that costly measures such as façade insulation should be reserved for situations where environmental limits are mandatory and rigid, and there are no other noise reduction targets. In this single objective situation, appropriate for CEA, façade insulation proved the most costeffective solution.

When the goal is to make effective use of public resources to reduce indoor residential noise annoyance for the areas/streets most affected, other measures have to be considered. The CBA of a mix of 30 per cent low-noise asphalts and 70 per cent façade insulation results in a benefit-cost ratio of approximately 1 . In situations where the authorities are willing to finance measures to reduce noise annoyance as a means of achieving the second objective, a noise abatement policy where 30 per cent of façade insulation projects are replaced by the laying of low-noise asphalts potentially makes much better use of public funds than 100 per cent façade insulation. However, it has to be said that estimates for combined asphalt/façade are more uncertain than estimates for 100 per cent façade.

It should be noted that double-porous asphalt was a less obvious alternative in 2003-2005, but has gained relevance after recent tests in Nordic conditions [9]; it would be wrong to conclude that the authorities had the option of pursuing this alternative in this first national noise-abatement operation. For pedagogical reasons, in this article we have considered only noise-reducing asphalts, in addition to façade insulation. For future actual projects, an inventory should be made of other at-source, propagation and possibly at-receiver measures to reduce indoor noise, and other promising alternatives included in the economic analyses.

\section{ACKNOWLEDGEMENT}

This main part of this study was funded by the Norwegian Research Council under the programmes MILGENHEL and PROFO. Additional funding was obtained from the Norwegian Public Roads Administration, the Ministry of Transport and Communication, the Norwegian Directorate for Health and Social Affairs, and the European Commission, through the project "Holistic and sustainable abatement of noise by optimized combinations of natural and artificial means" (HOSANNA), under Sustainable Surface Transport, Grant Agreement no. 234306. We are also grateful for helpful comments from the anonymous referees of this journal.

\section{REFERENCES}

[1] S. Solberg, R. Hagen, and R. Ommundsen, "Perceived noise reduction and secondary effects from the use of building insulation and barriers," Proceedings of the 12th International Congress on Noise Control Engineering. Edinburgh, UK, pp. 667-670, 1983.

[2] S. Fidell, and L. Silvati, "An assessment of the effect of residential acoustic insulation on prevalence of annoyance in an airport community," J. Acoust. Soc. Am., vol. 89, no. 1, pp. 244-247, 1991.

[3] W. A. Utley, I. B. Buller, E. C. Keighley, and J. Sargent "The effectiveness and acceptability of measures for insulating dwellings against traffic noise," J. Sound Vibr., vol. 109, pp. 1-18, 1985.

[4] A. H. Amundsen, R. Klæboe, and G. M. Aasvang, The Norwegian facade insulation study. "Efficacy of facade insulation in reducing noise annoyance due to road traffic," J. Acoust. Soc. Am., 2011, In press.

[5] A. H. Amundsen, "Effects of Facade Insulation on Annoyance and Sleep Disturbances", Proceedings of the 36th International Congress and Exposition on Noise Control Engineering, paper no. IN07_302, Istanbul, Turkey, 2007. Available on CD.

[6] E. J. Mishan, Cost-Benefit Analysis: an Informal Introduction, $4^{\text {th }}$ ed., London, UK: Unwin-Hyman, 1988.

[7] H. Høie, and S. H. (Eds.), "Natural resources and the environment 2008," Statistical Analysis, SA 109, Statistics Norway, Oslo/Kongsvinger, Norway, 2009.

[8] W. Kropp, T. Kihlman, J. Forssén, and L. Ivarsson, Reduction potential of Road Traffic Noise: a Pilot Study, Chalmers, Gothenburg, Sweden, 2007.

[9] R. Evensen, Miljøvennlige Vegdekker: Sluttrapport - Environmentally Friendly pavements: final report, Report 2562, Norwegian Public Roads Administration, Trondheim, Norway, 2009.

[10] U. Sandberg, "Abatement of traffic, vehicle, and tire/road noise the global perspective," Noise Control Eng. J., vol. 49, no. 4, pp. 170-181, Jul-Aug, 2001.

[11] P. Morgan, Ed., "Guidance manual for the implementation of lownoise road surfaces," Final report of EC Project sustainable Road Surfaces for Traffic Noise Control (SILVIA), Brussels, Belgium: Forum of European National Highway Research Laboratories, p. 317, 2006.

[12] E. Öhrström, A. Skånberg, H. Svensson, and A. GidlöfGunnarsson, "Effects of road traffic noise and the benefit of access to quietness," J. Sound Vibr., vol. 295, no. 1-2, pp. 40-59, 2006.

[13] O. Axelsson, B. Berglund, and M. E. Nilsson, "Towards green labelling of soundscapes in residential areas," G. Brambilla, C. Ianiello \& L. Maffei (Eds.), Euronoise 2003. Roma:Italian Association of Acoustics (AIA). [Available on CD, ISBN8888942-00-9].

[14] B. Berglund, and M. E. Nilsson, "On a tool for measuring soundscape quality in urban residential areas," Acta Acust. United Ac., vol. 92, no. 6, pp. 938-944, 2006.

[15] B. Berglund, M. E. Nilsson, and P. Pekala, "Towards Certification of Indoor and outdoor soundscapes," Proceedings of the 33rd International Congress and Exposition on Noise Control Engineering, Paper 516. Available on CD. Prague, Czech Republic 2004.

[16] E. Engelien, R. Klæboe, and M. Steinnes, Neighbourhood Sonoscapes - Context Sensitive Noise Impact Mapping, 12/2004, Statistics Norway, 2004.

[17] R. Klæboe, "Are adverse impacts of neighbourhood noisy areas the flip side of quiet area benefits?," Appl. Acoust., vol. 68, no. 5, pp. 557-575, 2007.

[18] R. Klæboe, E. Engelien, and M. Steinnes, "Context sensitive noise impact mapping," Appl. Acoust., vol. 67, no. 7, pp. 620-642, 2006.

[19] E. Öhrström, "Longitudenal survey on effects of changes in road traffic noise - annoyance, activity disturbances, and psycho-social well-being," J. Acoust. Soc. Am., vol. 115, no. 2, pp. 719-729, 2004.

[20] P. Morgan, Guidance Manual for the Implementation of Low-Noise Road surfaces, 2006/02, Forum of European National Highway Research Laboratories, Brussels, 2006.

[21] K. Veisten, and J. Akhtar, "Cost-benefit analysis of low-noise pavements: dust into the calculations," Int. J. Pavement Eng., vol. 12, no. 1, pp.75-86, 2011.

[22] B. Snilsberg, T. Myran, N. Uthus, J. Aurstad, "Evaluation of Different Laboratory Methods for Simulation of Pavement Wear and Road Dust Generation," Road Mater Pavement Desi, vol. 9, pp. 287-304, 2008.

[23] N. Raitanen, "Measuring of noise and wearing of quiet surfaces," Doctoral Dissertation, Civil and Environmental Engineering, Laboratory of Highway Engineering, Helsinki University of Technology, Helsinki, 2005.

[24] NPRA, Håndbok 140 - konsekvensanalyser - Handbook 140 Impact Assessment of Road Transport Projects, Public Roads Administration, Oslo, Norway, 2006.

[25] K. Veisten, L. E. Larsen, K. Sælensminde, H. Bendtsen, and A. Arnevik, "Cost-benefit analysis of noise-reducing pavements: simple calculations based on Norwegian data," in Network on European Communications and Transport Activities Research (NECTAR), Porto, Portugal, 2007. 
[26] D. de Grujiter, and E. Hageman, "A new and easy method for costbenefit analysis of noise measures along highways and railways.," Proceedings of the 39th International Congress and Exposition on Noise Control Engineering. Lisbon, Portugal, 2010.

[27] M. C. Weinstein, and W. B. Stason, "Foundations of costeffectiveness analysis for health and medical practices," N. Eng. J. Med., vol. 296, no. 13, pp. 716-721, 1977.

[28] H. M. Levin, Cost-Effectiveness: a Primer, Newbury Park, CA, USA: Sage Publications, 1983.

[29] P. D. Bailey, G. Haq, and G. A, "Mind the Gap!," Eur Environ., vol. 12 , no. 5, pp. 245-256, 2002.

[30] G. Myrdal, Monetary Equilibrium, London, UK: Hodge, 1939.
[31] P. Bickel, R. Friedrich, A. Burgess, P. et al., "Proposal for harmonised guidelines. Deliverable 5, Developing Harmonised European Approaches for Transport Costing and Project Assessment (HEATCO)," Project funded by the European Commission under the Transport RTD Programme. Institut für Energiewirtschaft und Rationelle Energieanwendung (IER), Universität Stuttgart, Stuttgart, Germany, 2006.

[32] B. J. O’Brien, M. F. Drummond, R. J. LaBelle, and A. Willan, "In search of power and significance: issues in the design of stochastic cost-effectiveness studies in health care.," Med. Care, vol. 32, pp. 150-163, 1994

[33] P. Corporation, “@Risk. Risk analysis and simulation. Add - inn for Microsoft Excel," Palisade, 2009.

(C) Klæboe et al.; Licensee Bentham Open.

This is an open access article licensed under the terms of the Creative Commons Attribution Non-Commercial License (http:/creativecommons.org/licenses/by-nc/ 3.0/) which permits unrestricted, non-commercial use, distribution and reproduction in any medium, provided the work is properly cited. 